Dokuz Eylül Üniversitesi-Mühendislik Fakültesi Fen ve Mühendislik Dergisi Cilt 20, Sayı 59, Mayıs, 2018
Dokuz Eylul University-Faculty of Engineering Journal of Science and Engineering Volume 20, Issue 59, May, 2018

DOI: $10.21205 /$ deufmd.2018205933

\title{
İzmir Körfezi için Rüzgar Potansiyeli Belirleme Ön Çalışması: 3 Boyutlu Hesaplamalı Akışkanlar Dinamiği Analizleri ile Rüzgar Verisinin Düzeltilmesi için Yerel Feribotlar Üzerindeki Akış Bozunumlarının Ölçülmesi
}

\author{
Şahin GÜNGÖR ${ }^{* 1}$, Ziya Haktan KARADENIZ ${ }^{1}$ \\ ${ }^{1}$ İzmir Katip Çelebi Üniversitesi, Mühendislik Fakültesi, Makina Müh. Bölümü, İZMİR \\ (ORCID: http://orcid.org/0000-0003-1833-1484, http://orcid.org/0000-0001-7850-7942)
}

(Alınış / Received: 24.03.2017, Kabul / Accepted: 02.10.2017, Online Yayınlanma / Published Online: 15.05.2018)

Anahtar Kelimeler Hava Akıs Bozunumları, Rüzgar Verilerinin Düzeltilmesi, Su üstü Rüzgar Enerji Potansiyeli.

Özet: Sürdürülebilir üretim sağlayan su üstü rüzgar enerjisi, çevre dostu teknolojisiyle gün geçtikçe önem kazanan yenilenebilir enerji kaynağıdır. Su üstü rüzgar potansiyelinin belirlenmesinde meteoroloji gözlem direkleri, uydu destekli donanımlar ve ses-ışı yoluyla tarama yapan cihazlar kullanılmaktadır. En klasik yöntem olan gözlem kuleleri uzun ölçüm periyotları sonucunda (en az 1 yıllık ölçüm) rüzgar potansiyeli belirlemek için kullanılır. Ses veya ışık yollu tarama cihazlarının kullanımı rüzgar potansiyelinin belirlenmesi için çok maliyetli yöntemlerdir. Uydu destekli donanımlar yardımıyla oluşturulan, geniş alanlarda potansiyel belirlemeye yarayan ve kullanımı gitgide yaygınlaşan rüzgar haritalarında ise çözünürlük çok düşüktür ve verilerin doğrulanması gerekir. Bu çalışmada, su üstü rüzgar enerjisi potansiyeli belirlenmesi çalışmalarında gemilerin kullanılması veya diğer metotlarla elde edilen su üstü rüzgar verilerinin gemiler yardımıyla doğrulanması fikri ortaya atılmıştır. İzmir Körfezinde yolcu taşımacıllğı için kullanılan katamaran tipteki feribotlar modellenerek, gemi üzerindeki hava akıș bozunumlarının ve anemometre bölgesindeki rüzgar hızı hatalarının, rüzgar hızı ve rüzgar yönlerindeki değişimlere bağlı olarak analizi ve hesabı amaçlanmıştır. Böylece, Körfezde sefer yapan gemiler yardımıyla su üstü rüzgar enerjisi belirleme çalıșmaları adına temel bir inceleme yapılmıștır.

\section{A Preliminary Offshore Wind Energy Potential Study for Izmir Bay: Quantifying the Airflow Distortion on Local Ferryboats for Adjustment of Wind Data by 3D CFD Analysis}

\section{Keywords}

Airflow

Distortion,

Adjustment of

Wind Data,

Offshore Wind
Abstract: Offshore wind energy, which provides sustainable production, is a renewable energy source that gains importance with its eco-friendly technology. Meteorological observation towers, satellite-based instruments, and sonic-light detection and ranging devices are used for determining the offshore wind 
Ş. GÜNGÖR vd. / İzmir Körfezi için Rüzgar Potansiyeli Belirleme Ön Çalışması: 3 Boyutlu HAD Analizi ile Rüzgar Verisinin Düzeltilmesi için Yerel Feribotlar Üzerindeki Akış Bozunumlarının Ölçülmesi

Energy Potential. energy potential. Observation towers, which is the most classical method, is used to determine the wind potential as a result of long measurement periods (at least 1 year). Usage of the sound or light detection and ranging devices is a costly method for determining wind energy potential. In the case of wind maps created with satellite-based equipment, which are used to determine potential in large areas and become increasingly common, the resolution is very low and the data must be verified. In this study, the idea of using ships in the wind energy potential studies or verifying offshore wind data obtained by other methods with the help of ships was proposed. The catamaran ships using for the passenger transportation in Izmir Bay were modelled and it is aimed to analyse and calculate the air flow distortions on the ship and the wind speed errors in the anemometer area depending on the changes in wind speed and wind direction. So, a basic investigation has been carried out on behalf of the studies about offshore wind energy potential with the help of ships operating in the Bay.

*Şahin GÜNGÖR, sahin.gungor@ikc.edu.tr

\section{Giriş}

Okyanus ve deniz üstü meteorolojik verilerin elde edilmesi çalışmaları on yıllardır insanoğlunun uğraş alanıdır. Su üstü alanların genişliği nedeniyle sabit meteorolojik istasyonlar ölçümlerin sağlıklı şekilde yapılmasında yetersiz kalmış ve özellikle ticari gemiler yardımıyla bu verilerin elde edilmesi, toplanması fikri ortaya çıkmıştır. Gemiler yardımıyla meteorolojik verilerin elde edilmesi amacıyla Okyanus Meteoroloji Gemileri (OWS) adı verilen ve donanımlı ölçüm cihazlarına sahip gemiler kullanılmıştır [1-8]. Ancak, bu gemilerin sayılarının az olması ve okyanus üstü ölçüm yapılacak alanların genişliği nedeniyle, sefer yapan ticari gemilerin (tanker, kargo, yük gemileri vb.) veri toplamada kullanılması için Dünya Meteoroloji Örgütü (WMO) tarafından Gönüllü Gözlem Gemileri (VOS) programı oluşturulmuştur. Programa dâhil olan on binlerce ticari gemiden elde edilen meteorolojik ölçüm verileri Uluslararası Kapsamlı Okyanus Veri Seti (ICOADS) tarafından toplanmış ve arşivlenmiştir [1-3] .

Gemi anemometreleriyle yapılan rüzgar ölçümlerinde, geminin kendi yapısından kaynaklanan akış bozunumlarının belirlenmesi verinin doğruluğu açısından son derece önemlidir. Literatürde, geminin kendi yapısından kaynaklı akış bozunumlarına dair çalışmalar hem rüzgar tüneli hem de hesaplamalı akışkanlar dinamiği (HAD) analizleriyle ortaya konulmuş olup, hata miktarları gemi şekil ve büyüklüğüne bağlı olarak hesaplanmıştır [1-9]. Ancak, bu çalışmalarda kullanılan modeller genellikle kargo, yük ve tanker gemilerini detaylı olmadan temsil eden dikdörtgen şeklindeki prizmalardır [1,34,7-8]. Hava akış bozunumlarının hesaplanmasına yönelik bu çalışmalarda genellikle gemi burnundan gelen akış için analizler yapılsa da, özellikle araştırma gemilerindeki ölçümlerin kritik olması nedeniyle bu gemilerde farklı rüzgar yönleri için de analizler yapılmıştır. $\mathrm{Bu}$ analizler, farklı yönlerden etkiyen rüzgar hızında geminin şekil ve büyüklüğüne bağlı olarak ivmelenme ve zayıflamalar 
Ş. GÜNGÖR vd. / İzmir Körfezi için Rüzgar Potansiyeli Belirleme Ön Çalışması: 3 Boyutlu HAD Analizi ile Rüzgar Verisinin Düzeltilmesi için Yerel Feribotlar Üzerindeki Akış Bozunumlarının Ölçülmesi

meydana geldiği gerçeğini ortaya koymuştur. Gemilerin su üstü rüzgar verilerinin toplanması amaciyla kullanılması, günümüzde denize kıyısı olan ülkelerde yaygınlaşan su üstü rüzgar türbinleri için enerji potansiyeli belirleme çalışmalarında da kullanılabileceği fikrini doğurmuștur. Ek bir donanım gerektirmeden ve yüksek çözünürlüklü rüzgar verisi elde etmeyi sağlayan gemi anemometreleri sayesinde, doğrulanmıș su üstü rüzgar enerji potansiyeli elde edilebilir. Ancak, bu verilerin elde edilmesinden önce gemi yapısından kaynaklanan akış bozunumlarının belirlenmesi gerekmektedir. $\mathrm{Bu}$ çalışmada, İzmir Körfezinde yolcu taşımacılığı amacıyla kullanılan katamaran tipteki feribotlar detaylı olarak modellenerek, gemi üzerindeki hava akıș bozunumlarının ve anemometre bölgesindeki rüzgar hızı hatalarının rüzgar hızı ve rüzgar yönlerindeki değişimlere bağlı olarak analizi ve hesaplanması amaçlanmıştır. Analizler sonucunda elde edilen hata payları ve bunların hız-yön ile ilişkileri gerek grafiksel gerekse de matematiksel olarak sunulmuştur.

\section{Materyal ve Metot}

$\mathrm{Bu}$ çalışmada, İzmir Körfezinde yolcu taşımacılığı için kullanılan katamaran gövdeli gemiler modellenmiş ve HAD analizi ile gemi üzerine etkiyen rüzgarda meydana gelen akış bozunum miktarları elde edilmiştir.

\subsection{Katamaran Gemi Modeli ve Akış Hacminin Tanımlanması}

İzmir Körfezinde kullanılan katamaran gövdeli gemiler $39 \mathrm{~m}$ tam boy uzunluğa ve $11,7 \mathrm{~m}$ genişliğe sahiptir. Gemi yüksekliği, su kesiminden ana direğin en üst noktasına kadar yaklaşık $11 \mathrm{~m}$ olup, anemometre yüksekliği 10,8 m' dir. Gemi yapısı nedeniyle meydana gelen rüzgar bozunumlarının en sağlıklı şekilde ölçülebilmesi için, katamaran gemi bir bilgisayar destekli çizim programı ile üç boyutlu ve bire bir ölçekle detaylı olarak modellenmiștir. Geminin ön güvertesinin sol uç kısmı, gerçekte yolcu platformu ekipmanlarının o kısımda bulunması nedeniyle kapalı modellenmiştir. Oluşturulan bu model Ansys CFX HAD programına aktarılarak, analizler için oluşturulan üç katmanlı silindirik bir akış hacminin (Şekil 1) tabanının tam ortasına yerleștirilmiștir. Akıș hacminin ilk katmanı yarıçapı 39 m (gemi uzunluğunda) ve yüksekliği 21,6 m (anemometre yüksekliğinin 2 katı) olan silindirik çekirdektir. Gemi modeli bu katmanın alt tabanının ortasında yer almaktadır. İkinci katman ise ilk katmanı saran bir yüzük şeklinde olup, yarıçapı 195 m (gemi uzunluğunun 5 katı) ve yüksekliği 21,6 m'dir. Son katmanın yarıçapı $195 \mathrm{~m}$ (gemi uzunluğunun 5 katı) ve yüksekliği ise 28,4 m (toplam çözüm hacmi yüksekliği 50 m'dir) olup, ilk iki katman üzerine yerleștirilmiștir.

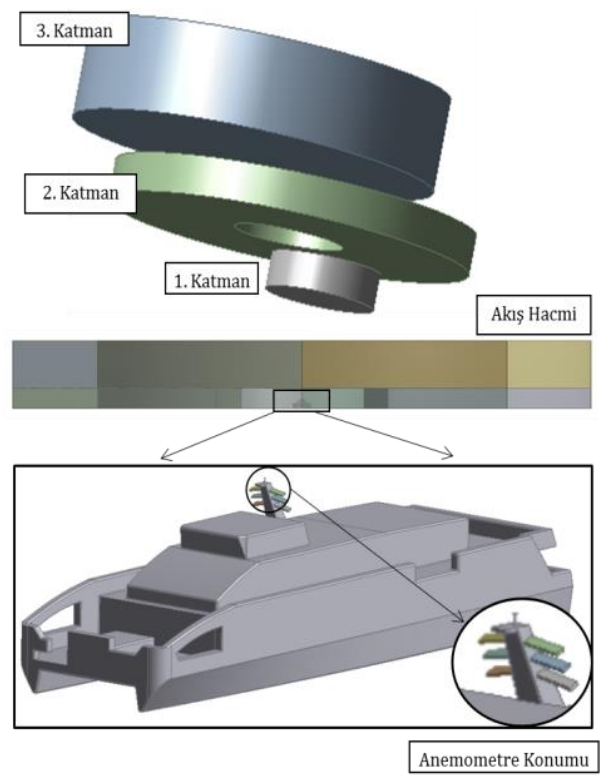

Şekil 1. Akıș hacmi, katmanları ve anemometre detayl. 
Ş. GÜNGÖR vd. / İzmir Körfezi için Rüzgar Potansiyeli Belirleme Ön Çalışması: 3 Boyutlu HAD Analizi ile Rüzgar Verisinin Düzeltilmesi için Yerel Feribotlar Üzerindeki Akış Bozunumlarının Ölçülmesi

Akışın en iyi şekilde incelenebilmesi için geniş bir silindirik kontrol hacmi olușturulmuș olup, ağ yapısını daha sağlıklı oluşturabilmek için akış hacmi katmanlara ayrılmıştır.

\subsection{Akıș Hacmindeki Ă̆ Yapısının Olușturulması ve Ă̆ Kalitesinin Belirlenmesi}

Bu çalışmada, akış hacmi içinde akışın en doğru şekilde incelenebilmesi amacıyla farklı büyüklükteki ağ yapıları üzerinde çalıșılmıștır. A $\breve{g}$ yapısının en sağlıklı şekillerde oluşturulması için akış hacmi katmanlara ayrılmıştır. Silindirik akış hacmi, 45 lik açılarla gelen rüzgarın kolay tanımlanabilmesi ve rüzgarın farklı yönlerden etkidiği tüm analizlerde ağ yapısının sabit tutulabilmesi için (ilk katman haricinde) 8 eşit parçaya bölünmüştür. Şekil 2'de gösterilen ă̆ yapısı incelendiğinde, geminin bulunduğu çekirdek katmanın üçgen prizma şeklindeki ağ yapısı ile detaylı olarak örüldügü ve bu bölgeden uzaklaștıkça ağ yapısının büyüdüğü görülmektedir.

Analizler için farklı büyüklükteki ağ yapıları denenerek ağdan bağımsızlık sağlanması amaçlanmıştır ve bunların sonuçları önceki çalışmalarda sunulmuştur [12,13]. Ancak, üzerinde çalışılan model için, literatürde sayısal veya deneysel veri olmadığından doğrulama çalışması için farklı bir gemi modeli kullanılmıştır. Referans çalışmadaki (Moat [4]) dikdörtgenler prizması şeklindeki bir akış hacmine yerleştirilmiş olan bir tanker modeli için elde edilen HAD sonuçları ile bazı deneysel çalışma sonuçları karşılaştırılmıştır. Deneysel çalışma kısmında hem laboratuvar ortamında parçacık görüntülemeli hı ölçümü yöntemi (PIV) ile hem de sahada yapılan ölçümler ile elde edilen hız dağılımı verisi bulunmaktadır.[4],
Doğrulama çalışmasında, referans çalışmadaki tanker modeli, silindirik akış hacmi içine yerleştirilerek farklı ağ büyüklükleri için incelenmiștir. Model, tanker geometrisi ile orantılı şekilde ve bu çalışmada incelenen katamaran ile yaklaşık boyutlara sahip olacak şekilde (tam boyu $37 \mathrm{~m}$ ) boyutlandırılmıştır. Hesaplamalı akış hacminin 2. ve 3 . katmanları düzenli ağ yapısıyla, çekirdek katman ise düzgün dörtyüzlü ağ yapısıyla örülmüștür. Tüm ağ yapılar için gemi üzerindeki eleman büyüklükleri referans çalışmaya uygun olarak 0.05 m'ye sabitlenmiştir. Yüzeyden itibaren ağ yapı büyüme oranı değiştirilerek, çekirdekteki eleman sayısı değiștirilmiștir. Böylece yüzeyden itibaren ağ yapı büyüklüğü değişiminin hız dağılımına etkisi incelenmiştir. Tablo 1' de farklı büyüme oranları için ăg yapılarındaki dügüum sayıları verilmiștir.

Tablo 1. Ağdan bağımsızlık denemelerinde kullanılan akış hacmi ağ sayıları.

\begin{tabular}{ccc}
\hline $\begin{array}{c}\text { Büyüme } \\
\text { Oranı }\end{array}$ & $\begin{array}{c}\text { Çekirdek } \\
\text { Katman } \\
\text { Dügüm } \\
\text { Sayısı }\end{array}$ & $\begin{array}{c}\text { Toplam } \\
\text { Dügüm } \\
\text { Sayısı }\end{array}$ \\
\hline 1,16 & 945.555 & 11.005 .734 \\
1,12 & 1.284 .710 & 11.342 .747 \\
1,08 & 2.050 .996 & 12.106 .381 \\
1.04 & 4.478 .471 & 14.529 .878
\end{tabular}

Tanker modeli için farklı büyüklükte ağ yapıları için analiz sonuçları Moat'ın [4] çalıșması ile karşılaştırılmak üzere, boyutsuz hız değerleri boyutsuz düşey konum $(\mathrm{z} / \mathrm{H})$ ile değişimi incelenmiştir. 
Ş. GÜNGÖR vd. / İzmir Körfezi için Rüzgar Potansiyeli Belirleme Ön Çalışması: 3 Boyutlu HAD Analizi ile Rüzgar Verisinin Düzeltilmesi için Yerel Feribotlar Üzerindeki Akış Bozunumlarının Ölçülmesi

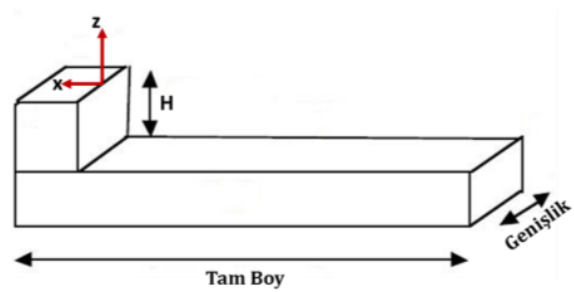

Şekil 2. Doğrulama analizlerinde kullanılan tanker modeli için temel ölçüler.

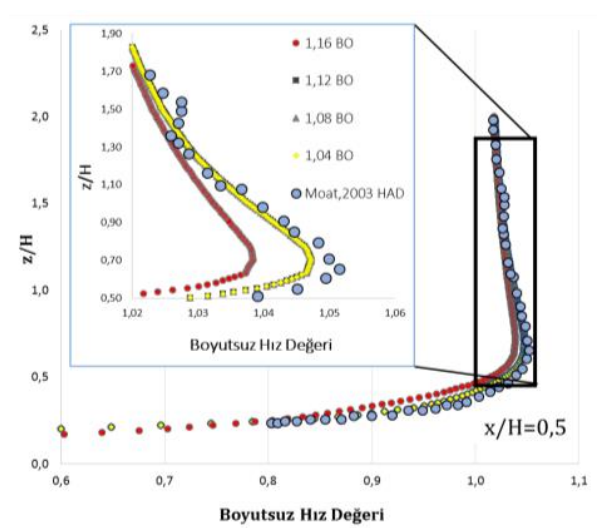

Şekil 3. Farklı büyüme oranları için analiz sonuçları.

Şekil 3'te, akış hacmine yerleştirilen tanker modeli üzerindeki akıș dağılımına ilişkin analiz sonuçları farklı ağ sayıları için gösterilmektedir. Burada, " $\mathrm{z}$ " geminin köprüsünden düșey konumu, " $\mathrm{H}$ " geminin güvertesinden köprüye kadar olan yüksekliği ve " $\mathrm{x}$ " ise gemi köprüsündeki yatay konumu temsil etmektedir. Analiz sonuçları, tanker modelinin köprü kısmının tam ortasındaki $(\mathrm{x} / \mathrm{H}=0,50 \mathrm{~m})$ bir dikme üzerinde elde edilmiş ve literatürdeki HAD sonucu ile karşılaştırılmıştır. Sonuçlar incelendiğinde 1,12 büyüme oranı ve daha ince ağ yapıları $(<1,12)$ için, literatürdeki HAD sonuçları ile uyumlu olduğu görülmektedir.

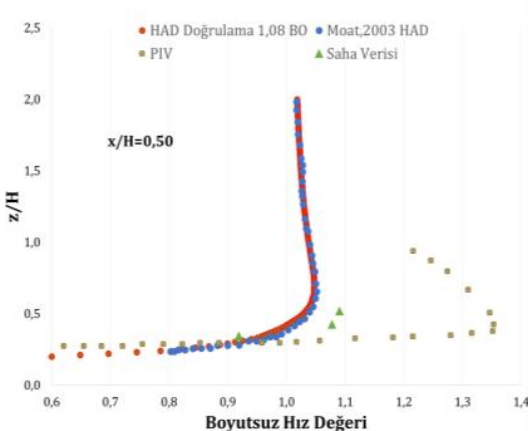

Şekil 4. HAD sonuçlarının literatürdeki HAD, PIV ve saha verileri ile karşılaştırılması.

Şekil 4'te HAD sonuçlarının, PIV ve saha verileri karşılaştırması sunulmuştur. Şekil 4'te gösterildiği üzere, silindirik akış hacmi içinde oluşturulan ağ yapısı (1,08 büyüme oranlı) ile elde edilen HAD sonuçları ile saha verileri arasındaki fark \%6'dan daha azdır. PIV sonuçları ve HAD sonuçları arasında ise büyük farklılıklar bulunmaktadır. Moat [4], ölçümlerdeki hatanın rüzgar tüneli kalibrasyonundan ya da duvar daralma etkisinden kaynaklanabileceğini belirtmiştir. Tanker modeli için yapılan ağdan bağımsızlık ve HAD doğrulama çalışmasıyla, silindirik akış hacmi içine yerleştirilen model için serbest rüzgarda meydana gelen ivmelenme ve yavaşlama bölgelerinin doğru şekilde belirlenebileceği anlaşılmıştır.

Aynı ă̆ sistematiği ile katamaran gövdeli gemi için gemi yüzeyleri 0,03 m’ye kadar incelen düzgün dörtyüzlü ă yapısı 1,08 büyüme oranı ile oluşturulmuştur. En küçük ağ boyutunun 0,05 m'den 0,03 m'ye kadar düşürülmesinin ve büyüme oranının referans çalışmayla uyumlu en büyük elemana sahip sonucu veren 1,12 değeri yerine 1,08 seçilmesinin nedenleri; tanker modeline göre daha karmaşık bir geometriye sahip olan katamaranın ağ yapı kalitesini arttırmak ve katamaran etrafındaki her noktadan sağlıklı şekilde veri alabilmektir. 
Ş. GÜNGÖR vd. / İzmir Körfezi için Rüzgar Potansiyeli Belirleme Ön Çalışması: 3 Boyutlu HAD Analizi ile Rüzgar Verisinin Düzeltilmesi için Yerel Feribotlar Üzerindeki Akış Bozunumlarının Ölçülmesi

Sonuç olarak, katamaran model için doğrulanan tanker modelindeki ağ yapı yaklaşımı ile yaklaşık $15,6 \times 10^{6}$ adet düğüm noktasına sahip bir ağ yapı kullanılmıștır. Hesaplamalı akış hacminin çekirdek kısmında ise yaklașık

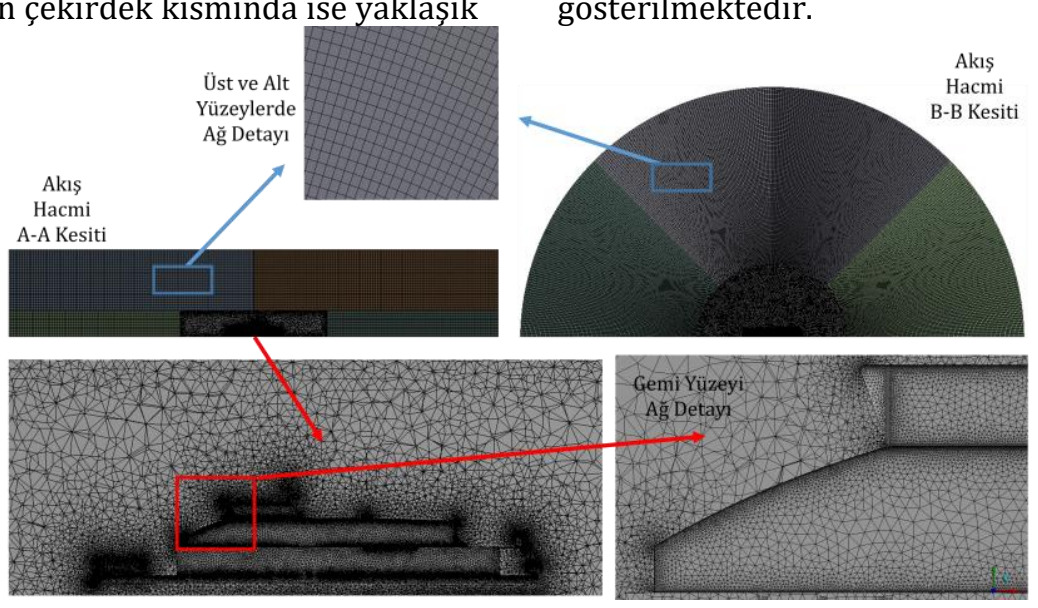

Şekil 5. Akış hacmi ve gemi yüzeyi için oluşturulan ağ yapısı gösterimi.

\subsection{Sınır Şartlarının Belirlenmesi}

Analizlerdeki giriş şartları belirlenirken rüzgar hızı atmosferik sınır tabaka koşulları dikkate alınarak Denklem 1' deki gibi tanımlanmıştır.

$\frac{U_{1}}{U_{2}}=\left(\frac{z_{1}}{z_{2}}\right)^{1 / 7}$

Analizlerde sıcaklık sabit olduğu $\left(25^{\circ} \mathrm{C}\right)$ için denklem (2) kullanılmıştır [10]. Bu denklemde " $z_{1}$ " $10 \mathrm{~m}$ referans yükseklik, " $U_{1}$ " bu yükseklikteki $10 \mathrm{~m} / \mathrm{s}$ serbest rüzgar hızl, " $z_{2}$ " akış hacmi içindeki herhangi bir düșey yükseklik ve " $U_{2}{ }^{\prime} z_{2}$ yüksekliğindeki rüzgar hızını temsil etmektedir.

Geminin en yüksek seyir hızı $16 \mathrm{~m} / \mathrm{s}$ ( 32 knot) olmasına karşın, ortalama seyir hızı yaklaşık $6 \mathrm{~m} / \mathrm{s}$ ( 11-12 knot)' dir [11]. Gemi, iskeleden kalkacağı ve iskeleye yanaşacağı süreler (yaklaşık birer dakika) haricinde bu hızda seyretmektedir. Bu nedenle analizlerde gemi hızı sabit ve $6 \mathrm{~m} / \mathrm{s}$ alınmıştır. $\mathrm{Bu}$
$7,2 \times 10^{6}$ adet düzgün dörtyüzlü ağ yapısına sahip düğüm noktası bulunmaktadır. Akış hacmimin katmanlarındaki ağ yapısı ve gemi yüzeyindeki ağ kalitesi Şekil 5'te gösterilmektedir.

çalışmada, gemi hızı sabit tutularak gemi burnundan gelen farklı hızlardaki $(0,5,10,15$ ve $20 \mathrm{~m} / \mathrm{s})$ rüzgar koșulları analiz edilmiș olup, rüzgar hızl ve anemometre bölgesindeki hata payı ilişkisi araştırılmıştır.

Farklı rüzgar yönleri için yapılan tüm analizlerde ise rüzgar hızı $10 \mathrm{~m}$ yükseklikte $10 \mathrm{~m} / \mathrm{s}$ olarak kabul edilmiştir [1-9,12-13]. Akış hacmi sekiz eşit parçaya bölündüğünden, $45^{\circ}$ lik her açı için ağ yapısı sabit tutularak, Denklem 2 ile kolaylıkla giriş ve çıkış tanımlamaları yapılmıştır.

$$
U_{\text {giris } \phi}=\sqrt{\left(U_{g}+U_{Y} \times \cos (\phi)\right)^{2}+\left(U_{Y} \times \sin (\phi)\right)^{2}}
$$

Bu denklemde " $U_{\text {girịg }}$ " sinır şartı olarak tanımlanan rüzgar hızl, “ $\phi$ ” geminin burnundan saat yönünde ölçülen açının radyan cinsinden değeri, " $U_{g}$ " gemi hızı ve " $U_{r}$ " ise atmosferik sinır tabaka koşulları dikkate alınarak düşey 
Ş. GÜNGÖR vd. / İzmir Körfezi için Rüzgar Potansiyeli Belirleme Ön Çalışması: 3 Boyutlu HAD Analizi ile Rüzgar Verisinin Düzeltilmesi için Yerel Feribotlar Üzerindeki Akış Bozunumlarının Ölçülmesi

eksende hesaplanan rüzgar hızıdır. Sınır şartları tanımlanırken, 1 atm basınç ve $25{ }^{\circ} \mathrm{C}$ sıcaklıktaki ortam koșulları ele alınmıștır. Analizlerde, bu koșuldaki hava için kayma gerilmesi taşınımı (shear stress transport (SST)) türbülans modeli kullanılmıştır. Çıkış sınır koşulları için $0 \mathrm{~Pa}$ bağıl basınç değeri ve serbest akış tanımlamaları kullanılmıştır. Akış hacminin tabanında yer alan yüzeyler kaymaz yüzey olarak, tavanında bulunan yüzeyler ise $0 \mathrm{~Pa}$ kayma gerilmeli serbest yüzey olarak tanımlanmıştır. Hız, basınç ve kinetik enerji için artık değerlerin $2 \times 10^{-4}$ değerine kadar düştüğü durumda sonuçların yakınsadığı kabul edilmiştir.

\section{Bulgular}

$\mathrm{Bu}$ bölümde, farklı rüzgar hıları ve farklı rüzgar yönleri için gemi yapısından kaynaklı akış bozunumları analiz edilmiş ve analizler sonucunda akışta meydana gelen hata payları grafiksel ve matematiksel olarak sunulmuştur.

\subsection{Farklı Rüzgar Hızları için Akış Bozunumlarının Hesaplanması}

$\mathrm{Bu}$ çalışmada, gemi üzerindeki ivmelenme ve yavaşlama bölgeleri farklı hız senaryoları için belirlenmiştir. Anemometre bölgesi rüzgar verilerinin toplanması amacıyla kritik olduğundan, özellikle o bölgedeki rüzgar hızları ve hata payları ile ilgilenilmiştir. $\mathrm{Bu}$ amaçla, model üzerindeki anemometre bölgesine $\mathrm{x}, \mathrm{y}$ ve $\mathrm{z}$ eksenlerinde 40' ar $\mathrm{cm}$ uzunluğunda çizgiler yerleștirilmiştir (Şekil 6). Böylece, bu çizgilerinden alınan verilerin ortalamaları ile geminin anemometre konumu ile aynı konumda olmak üzere en sağlıklı analiz sonuçları elde edilmiştir.

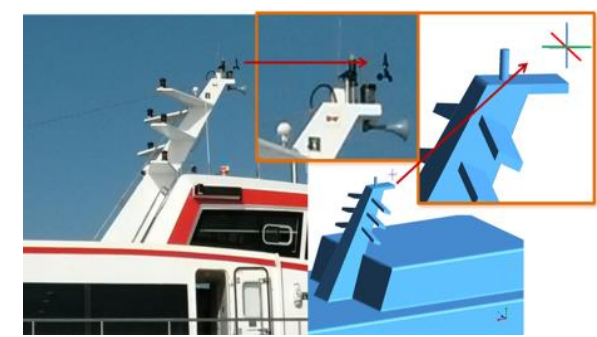

Sekil 6. Anemometre bölgesinin temsili ve model üzerindeki konumu.

Şekil 7' de geminin burnundan gelen akıș senaryosun için farklı hızlardaki rüzgar ve sabit gemi hızı $(6 \mathrm{~m} / \mathrm{s})$ kullanılmıştır. Geminin inşai yapısı nedeniyle akışta meydana gelen ivmelenme ve yavaşlama bölgeleri 0-30 $\mathrm{m} / \mathrm{s}$ hız aralığındaki sabit bir skala ile renklendirilerek gösterilmektedir. Farklı rüzgar açıları için giriş hız değerleri Denklem 3 ile hesaplanmıştır. Geminin burnundan gelen akış ve farklı rüzgar hızı senaryoları incelendiği için “Ф" açısının değeri sıfır alınmıştır. Gemi yapısına bağlı olarak analiz sonucunda hesaplanan bağıl rüzgar hızı değerleri Şekil 7'de görülmektedir. 
Ş. GÜNGÖR vd. / İzmir Körfezi için Rüzgar Potansiyeli Belirleme Ön Çalışması: 3 Boyutlu HAD Analizi ile Rüzgar Verisinin Düzeltilmesi için Yerel Feribotlar Üzerindeki Akış Bozunumlarının Ölçülmesi

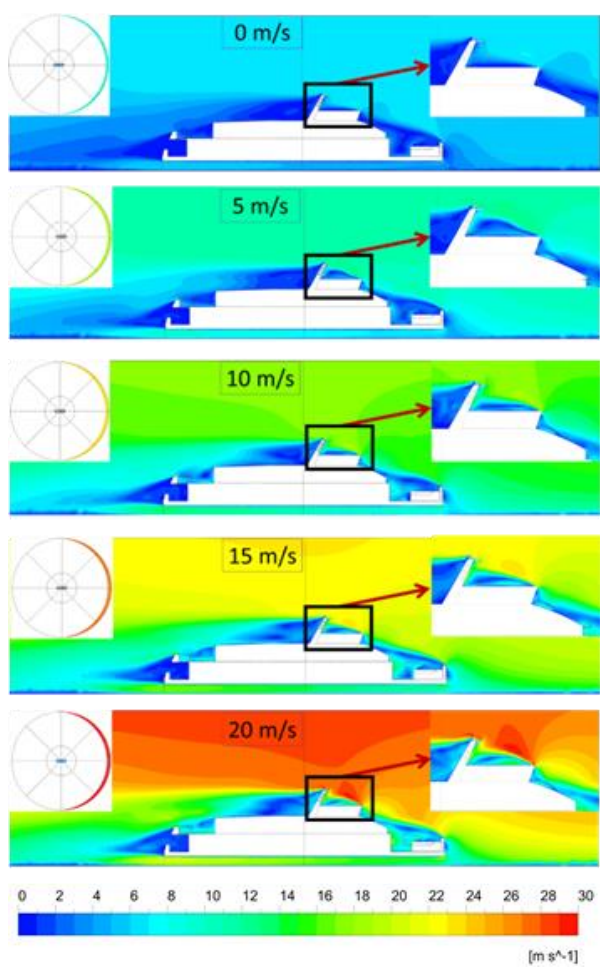

Sekil 7. Bağıl rüzgar hızının gemi bölgesindeki dağılımı

Şeklin üst orta kısmında rüzgar hızı değerleri, sol üst köşesinde akış hacmine etkiyen hız vektörü (üstten bakış), sağ üst köşesinde ise anemometre bölgesinin detayı gösterilmektedir. Tüm farklı hız senaryolarında, geminin ön ve arka güvertesi ile kaptan köşkünün art bölgesinde yavaşlamalar, geminin anemometre bölgesinde ivmelenmeler görülmektedir. Anemometre bölgesindeki hata payları, analiz sonuçları ve girişte tanımlanan bağıl rüzgar hızları kullanılarak Denklem 3 ile hesaplanmıştır.

Hata $=\frac{U_{h}-U_{m}}{U_{m}}$

$\mathrm{Bu}$ denklemde, " $V_{\hat{k}}$ " analizde hesaplanan bağıl hız değeri, " $U_{m s}$ " ise hata payının hesaplandığı seviyede girişte tanımlanan serbest rüzgar hızıdır.
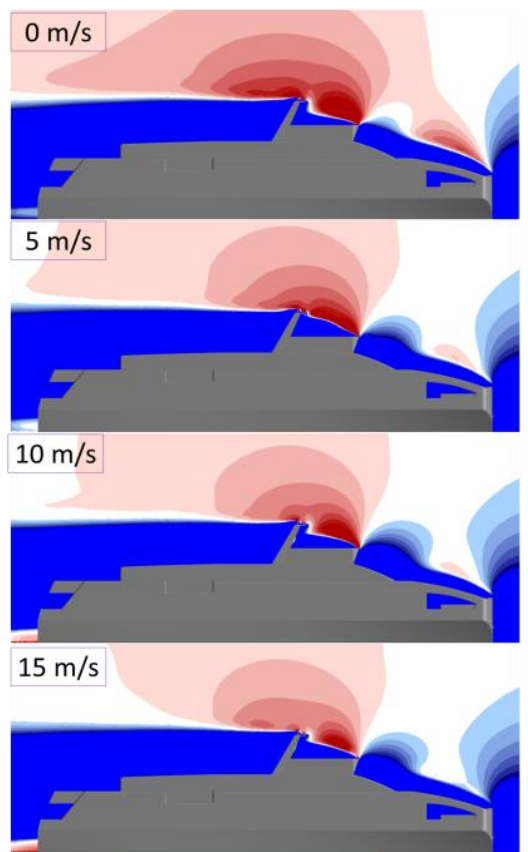

$20 \mathrm{~m} / \mathrm{s}$
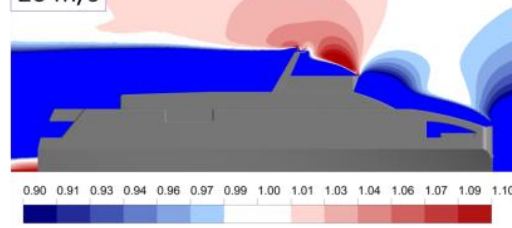

Şekil 8. Gemi yapısından kaynaklanan hata miktarlarının düssey eksende boyutsuz olarak gösterimi

Hata değerlerinin görsel olarak daha belirgin bir biçimde ortaya konulması amacıyla, gemi ve anemometre bölgesi çevresindeki ivmelenen ve yavaşlayan akış durumu Denklem 4 ile boyutsuzlaştırılmıștır.

$\mathrm{H}_{\mathrm{B} \text { oyutsuz }}=\frac{U_{h}}{U_{\infty}}$

Şekil 8'de gemi yapısı nedeniyle ivmelenen ve yavaşlayan akış ile serbest rüzgar hızındaki hata miktarları düşey eksende ve boyutsuz olarak 
Ş. GÜNGÖR vd. / İzmir Körfezi için Rüzgar Potansiyeli Belirleme Ön Çalışması: 3 Boyutlu HAD Analizi ile Rüzgar Verisinin Düzeltilmesi için Yerel Feribotlar Üzerindeki Akış Bozunumlarının Ölçülmesi

gösterilmektedir. Boyutsuz akış konturu, aynı hesaplama yöntemiyle anemometre yüksekliğinde ve yatay olarak (Şekil 9) da hesaplanmıștır. Boyutsuz şekiller incelendiğinde tüm analizler için anemometre bölgesinde ivmelenme, geminin ön ve arka güverteleri ile gemi direğinin art bölgesinde ise yavaşlama gerçekleştiği görülmektedir. Kaptan mahalinin ön kısmındaki eğik yüzey, geminin burnundan gelen akıșı ivmelendirerek anemometre bölgesinde daha yüksek akış hızı değerlerinin oluşmasına neden olmaktadır. Bununla birlikte geminin sahip olduğu keskin ve dik yüzeyler ise engel gibi davranarak akışa karşı yavaşlatıcı etki yaratmaktadır.

Farklı rüzgar hızlarında ve düşeyde boyutsuz hız değişimini gösteren Şekil 8 detaylı incelendiğinde, giriş bölgesinde tanımlanan serbest rüzgar hızı arttıkça anemometre bölgesinde meydana gelen ivmelenmenin neredeyse tüm senaryolarda azaldığı anlaşılmaktadır. Bununla birlikte, diğer hiz değerlerinden farklı olarak $0 \mathrm{~m} / \mathrm{s}$ rüzgar hızı için gemi burnundan itibaren ivmelenme bölgesi oluştuğu görülmektedir. Bunun nedeni, rüzgar hızı olmamasına rağmen, gemi hızının akışta meydana getirdiği etkidir.

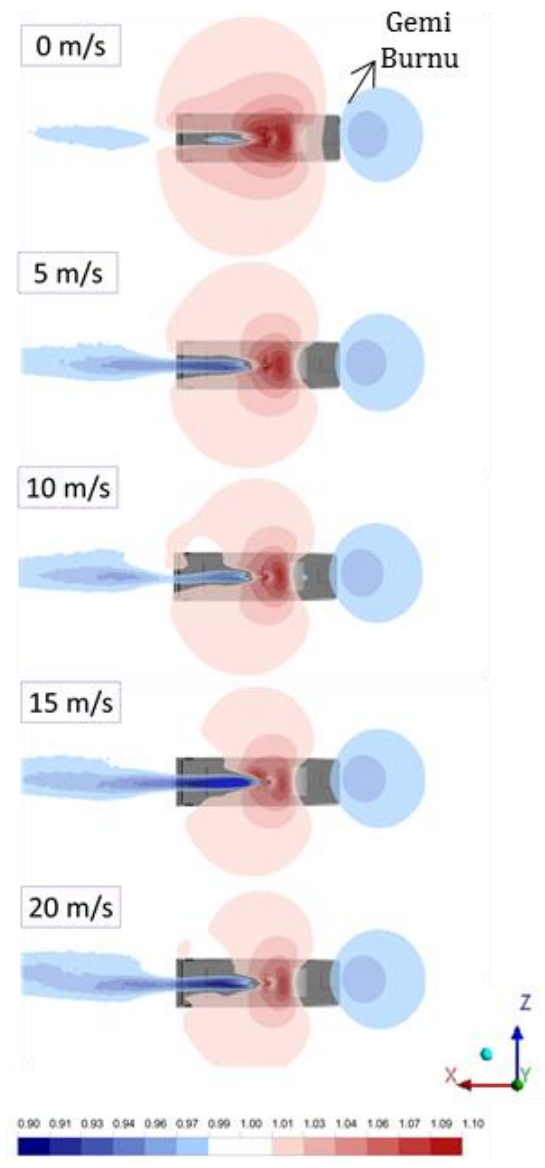

Şekil 9. Gemi yapısından kaynaklanan hata miktarlarının anemometre yüksekliğinde (yatayda) boyutsuz olarak gösterimi.

Şekil 9'da gösterilen yatay ve boyutsuz akış konturlarında, hız arttıkça anemometre bölgesindeki ivmelenmenin azaldığı ve gemi direği art bölgesindeki yavaşlamanın arttığ görülmektedir. Boyutsuz olarak hata miktarlarını gösteren şekillerde, geminin yapısı nedeniyle serbest akışın değişimini net olarak görebilmek için, serbest rüzgar hızının \% 10 azaldığı ve arttığı durumlar maviden kırmızı renge doğru gösterilecek şekilde renklendirilmiş ve serbest akışın $\% \pm 1$ değiştiği kısımlar ise şeffaf olarak gösterilmiştir. 
Ş. GÜNGÖR vd. / İzmir Körfezi için Rüzgar Potansiyeli Belirleme Ön Çalışması: 3 Boyutlu HAD Analizi ile Rüzgar Verisinin Düzeltilmesi için Yerel Feribotlar Üzerindeki Akış Bozunumlarının Ölçülmesi

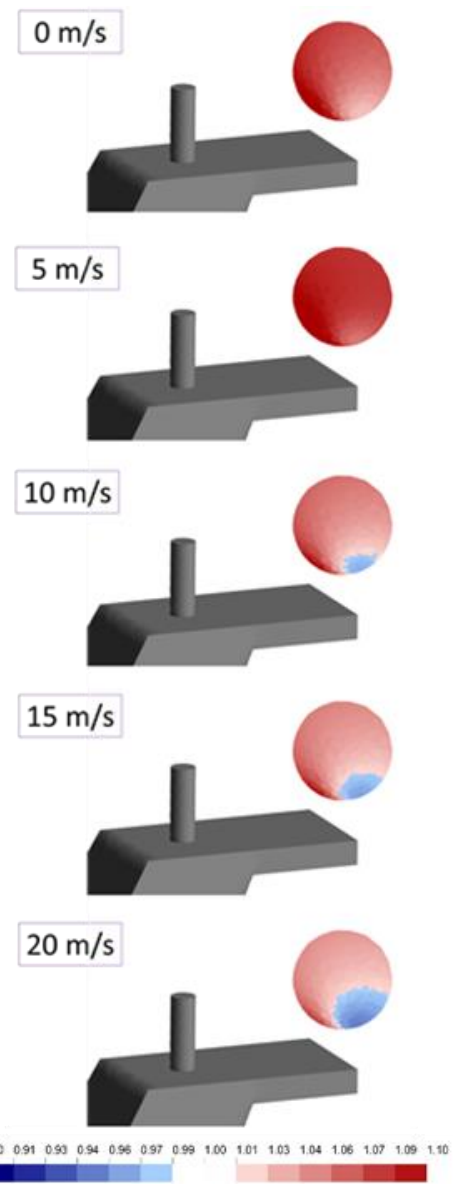

Şekil 10. Farklı rüzgar hızları için anemometre bölgesini temsil eden hacimdeki hatanın boyutsuz gösterimi.

Şekil 10'da katamaranda bulunan anemometre ile aynı konumda oluşturulan hacimler yardımıyla anemometre bölgesindeki boyutsuz akış dağılımı incelenmiştir. Farklı rüzgar hızları için yapılan analizlerde anemometre bölgesinde ivmelenme miktarı fazla olmasına rağmen yer yer yavaşlama etkileri de görülmektedir. Bu nedenle, en sağlıklı şekilde rüzgar verisi elde edebilmek için bu bölgeye $\mathrm{x}, \mathrm{y}$ ve $\mathrm{z}$ yönlerinde yardımcı çizgiler atılmış ve atılan çizgiler yardımıyla (her bir eksende 40 nokta) ortalama hata miktarı hesaplanmıștır.

Farklı hızlarda meydana gelen akış bozunumlarının tespitine dair yapılan analiz sonuçları aşağıdaki Tablo 2'de ve Șekil 11'de özetlenmektedir. Tablo 2'de belirtilen bağıl rüzgar hızı, $6 \mathrm{~m} / \mathrm{s}$ gemi hızı ve farklı rüzgar hızı değerleri için atmosferik sınır tabaka formülü Denklem 1 ve 2 kullanılarak hesaplanmıștır. 3 boyutlu hacimler incelendiğinde, en yüksek hata miktarının $5 \mathrm{~m} / \mathrm{s}$ rüzgar hızında tespit edildiği, daha sonraki hız değerleri için hata miktarının azaldığı, $10 \mathrm{~m} / \mathrm{s}$ ve üzeri rüzgar değerlerinde yavaşlama bölgelerinin oluştuğu görülmektedir. Şekil 11'de, rüzgar hızına bağlı olarak geminin burnundan gelen akış durumunda gemi yapısından kaynaklı olarak akışta meydana gelen bozunum miktarları gösterilmektedir.

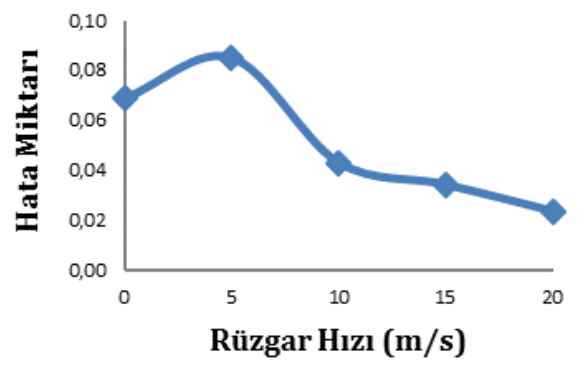

Şekil 11. Farklı rüzgar hızlarında meydana gelen hata miktarlarının grafiksel gösterimi

Rüzgar hızı arttıkça hata miktarında genellikle azalma meydana gelmektedir. Rüzgar hizı ve anemometre bölgesindeki hata miktarı arasındaki ilişki matematiksel olarak Denklem 5 ile ifade edilebilir.

Hata $=-0,00288 x+0,0795$ 
Ş. GÜNGÖR vd. / İzmir Körfezi için Rüzgar Potansiyeli Belirleme Ön Çalışması: 3 Boyutlu HAD Analizi ile Rüzgar Verisinin Düzeltilmesi için Yerel Feribotlar Üzerindeki Akış Bozunumlarının Ölçülmesi

Tablo 2. Farklı rüzgar hızlarında anemometre bölgesinde meydana gelen bozunum miktarı.

\begin{tabular}{cccc}
\hline Rüzgar Hızı (m/s) & Bağıl Rüzgar Hızı (m/s) & $\begin{array}{c}\text { Hesaplanan Rüzgar } \\
\text { Hızı (m/s) }\end{array}$ & Hata Miktarı \\
\hline 0 & 6,00 & 6,413 & 0,069 \\
5 & 11,06 & 12,000 & 0,085 \\
10 & 16,11 & 16,807 & 0,043 \\
15 & 21,17 & 21,894 & 0,034 \\
20 & 26,22 & 26,841 & 0,024
\end{tabular}

\subsection{Farklı Rüzgar Açıları için Akış Bozunumlarının Hesaplanması}

$\mathrm{Bu}$ çalıșmada, sabit gemi hızı ve ortalama serbest rüzgar hızı $(10 \mathrm{~m}$ yükseklikte $10 \mathrm{~m} / \mathrm{s}$ serbest rüzgar hızı) için farklı yönlerden gelen rüzgarın (Şekil 12) gemi yapısından kaynaklı olarak gemi üzerinde ve özellikle anemometre bölgesinde meydana getirdiği etkiler ve hata miktarları da analiz edilmiştir.

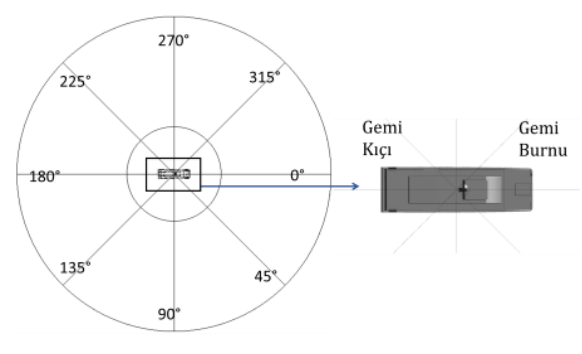

Şekil 12. Analizlerde kullanılan farklı rüzgar açılarının (saat yönünde) gösterimi. 
Ş. GÜNGÖR vd. / İzmir Körfezi için Rüzgar Potansiyeli Belirleme Ön Çalışması: 3 Boyutlu HAD Analizi ile Rüzgar Verisinin Düzeltilmesi için Yerel Feribotlar Üzerindeki Akış Bozunumlarının Ölçülmesi
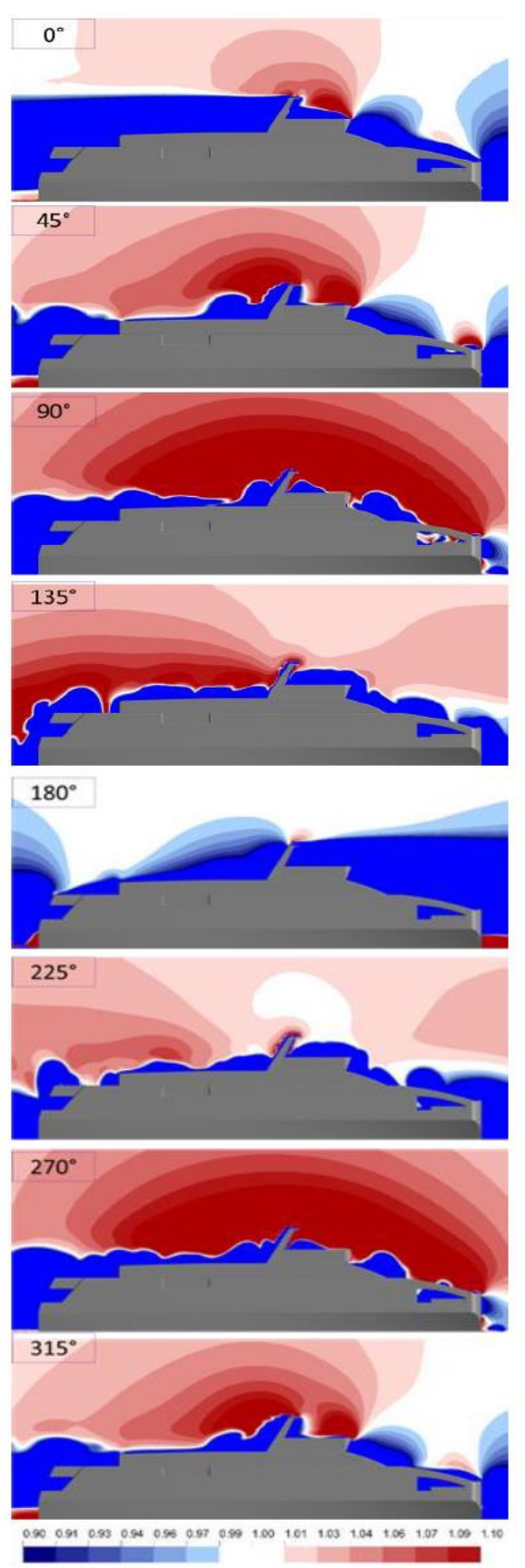

Şekil 13. Farklı rüzgar açlları $\left(0-315^{\circ}\right)$ için gemi üzerindeki akışın düşey eksende boyutsuz gösterimi.

Analiz sonuçları hem hesaplanan gerçek hız değerleri hem de yatay ve düşey düzlemlerde boyutsuz hız verileri ile gösterilmiștir. Şekiller $0-135^{\circ}$ ve 180 $315^{\circ}$ olmak üzere 2 kısımda incelenmiştir. Farklı rüzgar açıları için giriş hız değerleri denklem 2 ile hesaplanmıştır. Geminin ön güvertesinde bulunan ve yolcu indirmebindirme operasyonu için kullanılan platformun mekanik ekipmanları nedeniyle, katamaran modelin sol ön kısmı kapalı tutulmuştur. Bu yüzden analiz sonuçları tam simetriklik göstermemekle birlikte, geminin ana eksenine aynalanan açllar (45-315ㅇ 90 $270^{\circ} \mathrm{vb}$.) için çok yakın sonuçlar ortaya çıkmıştır.

Şekil 13'te farklı rüzgar açıları için düşey eksendeki boyutsuz hata miktarları gösterilmektedir. Boyutsuzlaştırma işlemi farklı rüzgar hızları için verilen denklemle aynı şekilde hesaplanmıştır. İzmir Körfezinde kullanılan katamaran gemilerin kaptan köşkünün ön kısmında bulunan eğik yüzey nedeniyle ön kısımlardan gelen rüzgar ivmelenmektedir. Bu nedenle, rüzgarın gemi burnuna herhangi bir açı ile geldiği tüm durumlarda akış ivmelenmiştir.

Geminin yan ve arka kısmındaki dik yüzeyler ise engel gibi davranmakta ve akışı zayıflatmaktadır. Geminin kıçından gelen akışta $\left(180^{\circ}\right)$, serbest rüzgar hızındaki en yüksek düşüş gözlemlenmiştir. Bunun nedeni, konumu geminin ana direğinin ön kısmında olan anemometrenin, kıçtan gelen akışta direğin art bölgesinde kalmasıdır. Bununla birlikte, geminin iskele ve sancağından gelen rüzgar analizlerinde geminin üst güverte ve anemometre bölgesinde yüksek ivmelenmeler görülmektedir. 
Ş. GÜNGÖR vd. / İzmir Körfezi için Rüzgar Potansiyeli Belirleme Ön Çalışması: 3 Boyutlu HAD Analizi ile Rüzgar Verisinin Düzeltilmesi için Yerel Feribotlar Üzerindeki Akış Bozunumlarının Ölçülmesi

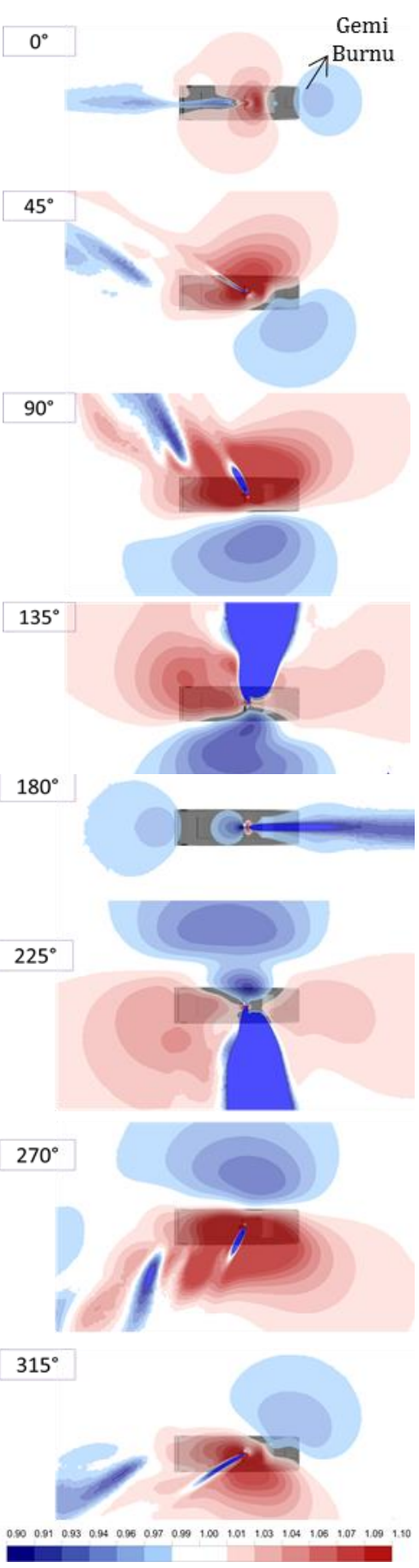

Şekil 14. Farklı rüzgar açlları $\left(0-315^{\circ}\right)$ için gemi üzerindeki akışın yatay eksende boyutsuz gösterimi.
Şekil 14'te anemometre yüksekliğine (yaklaşık 10,8 m) atılan yatay bir düzlem sayesinde, gemi üzerindeki akıș boyutsuz olarak gösterilmektedir. Yatay düzlemde hızlanma ve yavaşlama bölgeleri açıkça görülmektedir. Şekillerde, sağ taraf gemi burnunu, sol taraf gemi kıçını, üst taraf geminin iskelesini, alt taraf ise geminin sancağını göstermektedir. Analizlerde gemi hareketli olarak $(6 \mathrm{~m} / \mathrm{s})$ kabul edildiği için, elde edilen analiz sonuçlarındaki ivmelenme ve yavaşlama bölgeleri aynı zamanda bağll rüzgar yönünü de göstermektedir. Farklı rüzgar yönlerinin incelendiği tüm analizlerde, bağıl rüzgarın etkidiği yönde genellikle zayıflama tersi yönde ise ivmelenme görülmektedir. Geminin ana eksenine (burundan kıça yatay eksen) aynalanmış açllarda büyük benzerlikler görülmekle birlikte, geminin simetrik olmaması nedeniyle akışta farklılıklar da meydana gelmiştir.

Şekil 15'te serbest rüzgar hızındaki ivmelenme ve yavaşlama bölgeleri anemometre ile aynı konumda oluşturulan temsili hacim üzerinde gösterilmektedir. Farklı giriş hızları için yapılan akış analizlerinde büyük farklılıklar gözlemlenmezken, farklı yönlerden etkiyen rüzgar için yapılan analizlerde farklılıklar son derece fazladır. Analiz sonuçları incelendiğinde, rüzgarın geminin kıçından etkidiği durum hariç $\left(180^{\circ}\right)$ diğer tüm durumlarda akışta meydana gelen hatanın ivmelenme yönünde olduğu görülmektedir. Geminin kıçından gelen serbest rüzgar hızında yavaşlama olmasının başlıca nedeni, geminin arka güvertesini çevreleyen keskin yüzeylerdir. Ayrıca anemometrenin bulunduğu ana direk, arkadan gelen rüzgarın anemometreye gelişini engellemektedir. 
Ş. GÜNGÖR vd. / İzmir Körfezi için Rüzgar Potansiyeli Belirleme Ön Çalışması: 3 Boyutlu HAD Analizi ile Rüzgar Verisinin Düzeltilmesi için Yerel Feribotlar Üzerindeki Akış Bozunumlarının Ölçülmesi

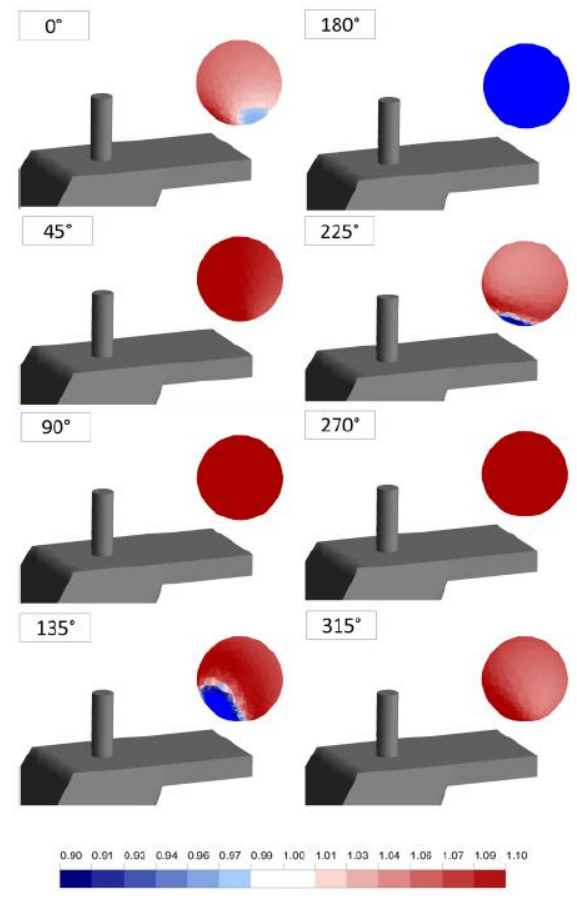

Şekil 15. Farklı rüzgar açıları $\left(0-315^{\circ}\right)$ için anemometre bölgesini temsil eden hacimdeki hata miktarlarının boyutsuz gösterimi.
Şekil 15'te, hacimsel olarak ve anemometre ile aynı konumda temsil edilen kritik bölge için, farklı açılarda yapılan analizler sonucu elde edilen hata miktarları Tablo 3'te sunulmaktadır. Anemometre bölgesi için diğer boyutsuz hız analizleriyle aynı ölçeklendirme yapılmıştır. Tablo 3' de yer alan hata miktarı değerleri pozitif ise akıșta meydana gelen ivmelenmeyi, negatif ise yavaşlamayı göstermektedir.

Tablo 3'teki açılar gemi burnundan saat yönünde ilerleyerek, Şekil 12'de gösterildiği şekilde belirlenmiştir. " $U_{10.8}{ }^{I}$ anemometre yüksekliğindeki bağıl serbest rüzgar hızıdır. Hız ve hata değerleri anemometre bölgesine 3 boyutta atılan çizgiler (Şekil 6) sayesinde her bir eksen için ve değerlerin ortalamaları alınarak verilmiştir. Anemometre bölgesindeki ortalama hata miktarı ise $x, y$ ve $z$ eksenlerindeki hata miktarlarının aritmetik ortalaması alınarak elde edilmiştir.

Tablo 3. Farklı rüzgar açıları için anemometre bölgesinde meydana gelen bozunum miktarı.

\begin{tabular}{|c|c|c|c|c|c|c|c|c|}
\hline \multirow[b]{2}{*}{$A c ̧ ı$} & \multirow[b]{2}{*}{$U_{108}(m / s)$} & \multicolumn{3}{|c|}{$\operatorname{Uort}(\mathrm{m} / \mathrm{s})$} & \multicolumn{4}{|c|}{ Hata Mikarı } \\
\hline & & $x$ & $y$ & $z$ & $x$ & $y$ & $z$ & Ort. \\
\hline $0,360^{\circ}$ & 16,111 & 16,837 & 16,806 & 16,778 & 0,045 & 0,041 & 0,043 & 0,043 \\
\hline $45^{\circ}$ & 14,967 & 16,557 & 16,514 & 16,613 & 0,106 & 0,110 & 0,103 & 0,107 \\
\hline $90^{\circ}$ & 11,757 & 13,822 & 13,776 & 13,844 & 0,176 & 0,178 & 0,172 & 0,175 \\
\hline $135^{\circ}$ & 7,241 & 7,907 & 7,876 & 7,727 & 0,092 & 0,067 & 0,088 & 0,082 \\
\hline $180^{\circ}$ & 4,111 & 2,430 & 3,336 & 2,773 & $-0,409$ & $-0,325$ & $-0,188$ & $-0,308$ \\
\hline $225^{\circ}$ & 7,241 & 7,804 & 7,756 & 7,578 & 0,078 & 0,047 & 0,071 & 0,065 \\
\hline $270^{\circ}$ & 11,757 & 14,134 & 14,083 & 14,168 & 0,202 & 0,205 & 0,198 & 0,202 \\
\hline $315^{\circ}$ & 14,967 & 16,235 & 16,194 & 16,290 & 0,085 & 0,088 & 0,082 & 0,085 \\
\hline
\end{tabular}




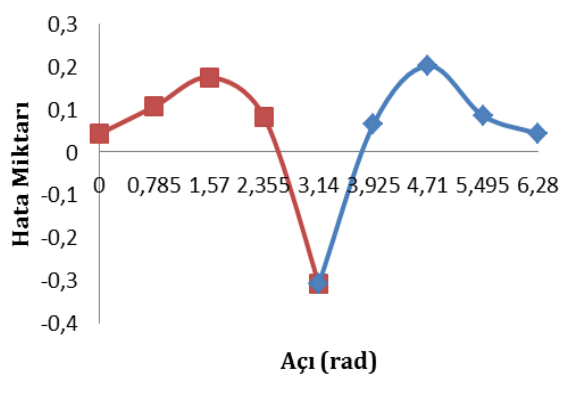

Şekil 16. Farklı rüzgar açılarında meydana gelen hata miktarlarının grafiksel gösterimi.

Şekil 16'da, farklı rüzgar yönlerindeki hata miktarları ve bağıl rüzgar hızları grafiksel olarak gösterilmiştir. Bağıl rüzgar hızları (2) numaralı denklem ile hesaplanmıştır. Hata miktarları incelendiğinde $0-180^{\circ}$ ve $180-360^{\circ}$ arasında büyük benzerlik görülmektedir. Bu çalışmada, rüzgar yönüne bağlı olarak anemometre bölgesindeki hata miktarının matematiksel ifadesi de elde edilmiştir.

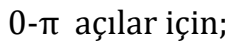

Hata $=-0,1237 x^{2}+0,296 x+0,0126$

$\pi-2 \pi$ açllar için;

Hata $=-0,1254 x^{2}+1{ }_{x} 2735 x-3,0434$

5, 6 ve 7 numaralı denklemler sayesinde gemi İzmir Körfezinde seyir halindeyken ve rüzgar hızları ile yönleri bildiğinde, anemometrenin okuduğu rüzgar hızı değerleri gemi yapısından kaynaklı akış bozunumlarından arındırılarak doğru olarak tespit edilebilir. Böylelikle, İzmir Körfezindeki herhangi bir noktadaki su üstü rüzgar verisinin ek donanımlar gerektirmeden doğrulanmış olarak elde edilmesi sağlanmaktadır.

\section{Tartıșma ve Sonuç}

$\mathrm{Bu}$ çalışmada, İzmir Körfezinde sefer yapan yolcu gemileri kullanılmış ve Körfez rüzgar enerji potansiyelinin tespiti hususunda bir ön çalışma olarak gemi üzerinde aerodinamik analiz yapılmıştır. Literatürdeki akış bozunumlarının incelendiği hiçbir çalışmada katamaran gövdeli gemiler kullanılmamıştır. Bunun nedeni, bu tip konforlu gemilerin yüksek maliyet ve zor işçilik nedenleriyle son yıllarda yaygınlaşmasıdır. Gemi modeli oluşturulurken çizim bire bir ölçekte ve detaylı olarak oluşturulmuştur. Diğer çalışmaların aksine gemi modeli dikdörtgen akış hacmi yerine silindirik akış hacmine yerleştirilmiştir. İlk kez denenen bu model sayesinde akıș $360^{\circ}$ olarak ve sabit ağ yapısı ile incelenebilmiştir. Silindirik akış hacmi katmanlara ayrlarak, gemiye yakın bölgelere detaylı ağ modeli uygulanmıștır. Ayrıca akış hacmi, gemi modelinin bulunduğu çekirdek katman hariç 8 eş parçaya ayrılarak, sabit ağ yapısı ve gemi yönü ile sadece giriş parçaları değiştirilerek $45^{\circ}$ lik rüzgar yönleri için analizler yapılmıştır.

Farkı yönlerden gelen rüzgar analizi sonuçları ile geminin yapısı nedeniyle akışta meydana gelen ivmelenme ve yavaşlama bölgeleri tespit edilmiş ve anemometre bölgesindeki bozunum değerleri hesaplanmıştır. Sonuçlara göre, gemi kıçından $\left(180^{\circ}\right)$ gelen akış için \% 30' a varan yavaşlamalar görülmüștür. Geminin burnundan gelen akış için \% 4.3, saat yönünde $45^{\circ}$ için yaklaşılk olarak \% 10, $135^{\circ}$ için \% 8.2, $225^{\circ}$ için \% 6.5 ve $315^{\circ}$ için \%8.5 ivmelenme tespit edilmiștir. Geminin bordalarından (90 ve $270^{\circ}$ ) gelen akış durumunda ivmelenme en yüksek değerlere ulaşmış ve \% 20' ye varan ivmelenmeler görülmüştür. 
Ş. GÜNGÖR vd. / İzmir Körfezi için Rüzgar Potansiyeli Belirleme Ön Çalışması: 3 Boyutlu HAD Analizi ile Rüzgar Verisinin Düzeltilmesi için Yerel Feribotlar Üzerindeki Akış Bozunumlarının Ölçülmesi

Literatürde farklı rüzgar hızları için yapılan çalışmalar son derece azdır. Bunun nedeni, farklı rüzgar hızlarındaki analiz sonuçlarının küçük farklılıklar göstermesidir. $\mathrm{Bu}$ çalışmada, geminin Körfezdeki ortalama seyir hızı $(6 \mathrm{~m} / \mathrm{s})$ sabit tutularak, farklı rüzgar hızlarında ve geminin burnundan gelen akıș durumu için analizler yapılmıştır. Analiz sonuçları ile \%1-\%4 arasında bir bozunum farkı tespit edilmiș ve bu sonuçlar matematiksel olarak da ifade edilmiştir.

Günümüzde uydular yardımıyla rüzgar verisi elde etme yöntemi [14] yaygın olarak kullanılmakla birlikte, bu verilerin çözünürlüğü son derece düşüktür. $\mathrm{Bu}$ nedenle bu verilerin doğrulanması verinin güvenilirliği açısından son derece önemlidir. $\mathrm{Bu}$ çalışma sayesinde, yaz aylarında iç körfezin neredeyse tamamında faaliyet gösteren katamaran gövdeli gemiler üzerindeki akıșın analizleri yapılarak, İzmir Körfezinde herhangi bir noktadaki rüzgar verisinin sağlıklı şekilde elde edilmesi sağlanmaktadır. Ayrıca, herhangi bir ek donanım ve maliyet gerektirmeden, sadece gemi üzerindeki anemometreler kullanilarak toplanan veriler, analiz sonuçları ile arındırılarak doğrulanmış rüzgar verileri elde edilebilecektir.

\section{Kaynakça}

[1] Moat, B. I., Yelland, M. J., Molland, A. F., 2004. Possible Biases in Wind Speed Measurements from Merchant Ships, Southampton Oceanography Centre, Southampton, United Kingdom.

[2] Kent, E.C., Berry, D.I., 2005. Quantifying Random Measurement Errors in Voluntary Observing Ships' Meteorological
Observations, s. 843-856. DOI: 10.1002/joc.1167.

[3] Moat, B.I., Yelland, M.J., Pascal, R.W., Molland, A.F., 2005. An Overview of the Airflow Distortion at Anemometer Sites on Ships, s. 997-1006. DOI: 10.1002/joc.1177.

[4] Moat, B.I., 2003. Quantifying the Effects of Airflow Distortion on Anemometer Wind Speed Measurements from Merchant Ships, University of Southampton, School of Engineering Sciences Faculty of Engineering And Applied Science, PhD Thesis, Southampton.

[5] Taylor, P.K., Kent, E.C., Yelland, M.J., Moat, B.I., 1997. The Accuracy of Marine Surface Winds from Ships and Buoys, Southampton Oceanography Centre, United Kingdom.

[6] Thomas, B.R., Kent, E.C., Swail, V.R., 2005. Methods to Homogenize Wind Speeds from Ships and Buoys, s. 979-995. DOI: 10.1002/joc.1176

[7] Moat, B.I., Yelland, M.J., Pascal, R.W., Molland, A.F., 2006. Quantifying the Airflow Distortion over Merchant Ships. Part I: Validation of a CFD Model, Journal of Atmospheric and Oceanic Technology, United Kingdom.

[8] Moat, B.I., Yelland, M.J., Molland, A.F., 2006. Quantifying the Airflow Distortion over Merchant Ships. Part II: Application of the Model Results, Journal of Atmospheric and Oceanic Technology, United Kingdom.

[9] Moat, B.I., Yelland, M.J., 2015. Airflow Distortion at Instrument 
Ş. GÜNGÖR vd. / İzmir Körfezi için Rüzgar Potansiyeli Belirleme Ön Çalışması: 3 Boyutlu HAD Analizi ile Rüzgar Verisinin Düzeltilmesi için Yerel Feribotlar Üzerindeki Akış Bozunumlarının Ölçülmesi

Sites on the RRS James Clark Ross during the WAGES Project, National Oceanography Centre, Southampton, United Kingdom.

[10] Dünyada ve Türkiye'de Rüzgar Enerjisi Kullanımı. http://web.itu.edu.tr/ kaymak/im ages/windpower.html (Erişim Tarihi: 13.10.2015).

[11] Marine Trafik internet sitesi. http://www.marinetraffic.com/en /ais/home/centerx:27/centery:38 Lzoom:9. (Erişim Tarihi: 19.12.2015).

[12] Z.H., Karadeniz, Ş., Güngör, 2016. A Preliminary Offshore Wind Energy Potential Study for Izmir Gulf; Can We Use Local Ferryboats for Obtaining Wind Data?. Ege Energy Symposium and Exhibition, 11-13 May, p. 1128-1134, Afyon.

[13] 14Z.H., Karadeniz, Ș., Güngör, 2016. Quantifying Airflow Distortion around Anemometer Sites on a Catamaran. GMO-Shipmar-16, 8-9 December, paper 69, Istanbul.

[14] Soukissian, T.H., Papadopoulos, A., 2015. Effects of Different Wind Data Sources in Offshore Wind Power Assessment, s. 101-114, Renewable Energy. 